\title{
CONTRIBUIÇÃO DA DIVULGAÇÃO E POPULARIZAÇÃO CIENTÍFICA DURANTE A FORMAÇÃO INICIAL DE PEDAGOGOS NO ENSINO DE CIÊNCIAS
}

\section{CONTRIBUTION TO SCIENTIFIC POPULARIZATION AND PROPAGATION DURING THE INITIAL TRAINING OF TEACHERS IN SCIENCE TEACHING}

Thiago Emmanuel Araújo Severo, Luciane Schulz

Universidade Federal do Rio Grande do Norte

E-mail: thiagosev@gmail.com, luciane.schulz19@gmail.com

\section{Resumo}

O presente artigo relata os resultados do projeto Essa Semana na Ciência, realizando entre os semestres de 2014.1 a 2015.1, utilizado como ferramenta para o Ensino de Ciências no curso de Pedagogia da Universidade Federal do Rio Grande do Norte, campus Natal. Semanalmente os alunos publicaram em forma de vídeo, resumos dos acontecimentos do mundo científico, após visitarem e pesquisarem cerca de 9 portais de divulgação científica, totalizando 148 matérias. Por meio desse projeto, evidenciou-se que o envolvimento dos alunos com atividades associadas a produção, disseminação e uso da narrativa científica, são componentes indispensáveis para a construção do conhecimento científico e ampliação do diálogo destes com a sociedade.

Palavras-chave: ensino de ciências. formação inicial. popularização da ciência.

\section{Abstract}

This work shows the results obtained in Project "Essa Semana na Ciência" fulfilled between the 2014.1 and 2015.1 semesters, used as teaching tools for the Science Teaching at Pedagogy Course at Universidade Federal do Rio Grande do Norte, Campus Natal. Every week, the students published as a video format, abstracts about events in scientific word, after they visited and investigated nine scientific popularization sites, totalizing 148 reports. Through this project, it was evidenced that the involvement of students with activities associated with production, propagation and scientific narrative are essential components to the construction of scientific knowledge and to magnification of their dialog with the society.

Palavras-chave: popularization of science. science teaching. initial training. 


\section{INTRODUÇÃO}

As aulas de ciências são espaços híbridos experimentais, como laboratórios, onde são testadas, demonstradas e experimentadas ideias, modelos e teorias. São o local próprio para a empiria do conhecimento, onde o estudante aprende através do método científico possibilidades de narrar o mundo, abrindo um diálogo com a natureza a partir de novas vias de entendimento. De acordo com Morin (2003), se pudermos atribuir um objetivo ao conhecimento humano e à necessidade de criar esse diálogo com a natureza, seria o de

abrir, e não fechar o diálogo com esse universo. O que quer dizer: não só arrancar dele o que pode ser determinado claramente, com precisão e exatidão, como as leis da natureza, mas, também, entrar no jogo do claro-escuro que é o da complexidade (MORIN, 2003, p. 171).

Abrir o diálogo com a natureza significa, antes de qualquer coisa, estar apto a escutá-la. Nas sociedades modernas as ciências passaram a ser grandes chaves de decifração para a natureza. Os resultados das pesquisas são, em grande parte, disseminadas através de veículos como periódicos e jornais especializados em números astronômicos. As ciências estão em constante modificação, e o conhecimento científico constantemente modificado e atualizado através desses veículos de publicação.

Mas como dar conta dessa grande quantidade de informação? De acordo com Villani e Pacca (1997), a finalidade do ensino de ciências é "aproximar o estudante do conhecimento científico continuamente reformulado e aumentado" no qual a "atuação do professor deve ser coerente com este propósito" (VILLANI \& PACCA, p. 6). Nesse sentido, torna-se necessário que a forma de construir esse conhecimento científico, assim como os produtos dessas investigações estejam disponíveis para alunos e professores.

Vivemos na era informacional onde a sua interpretação e inteligibilidade são pontos de estrangulamento e não o seu acesso. A problemática hoje não reside na facilidade de acesso ao conhecimento, mas em entender quais e como esses conhecimentos são pertinentes para 
nossas vidas. De acordo com Reis e Gonçalves (2000) mesmo com o reconhecimento da necessidade e relevância da ciência para nossa sociedade ainda existem numerosas barreiras entre "a descoberta e o conhecimento científico, de um lado, e sua comunicação e absorção pelo público de outro" (REIS ; GONÇALVES, 2000, p. 79).

Essas barreiras são constatadas, a partir dos mesmos mecanismos, nos trabalhos de Bueno (BUENO, 2002; 2012; 2013). Segundo o autor, nosso país sofre grandes dificuldades quanto à aproximação ao conhecimento científico e quanto a sua apreciação pelo público. A falta de inteligibilidade que dificulta o acesso ao conhecimento científico em centros de formação e em escolas, diretamente para as mãos dos professores de ciências, é certamente uma situação preocupante, visto que "a partilha do saber inclui-se, sem dúvida, entre as funções sociais mais importantes no processo de democratização do conhecimento" (BUENO, 2002, p. 229).

Para isso, segundo o autor,

Urge estabelecer uma autêntica "cultura de comunicação" nos centros geradores de ciência e tecnologia em nosso País, porque universidades, institutos de pesquisa e empresas comprometidas com a produção de ciência e a tecnologia ainda são tímidas em sua tarefa de divulgar (BUENO, 2013, p. 5).

No sentido de contribuir para a aproximação dos professores de ciências ao conhecimento científico e tendo em vista a necessidade de uma rede de acesso entre esse conhecimento e os alunos de licenciatura em pedagogia, criou-se o projeto de divulgação e popularização científica Essa Semana na Ciência. O projeto dos alunos de Pedagogia da Universidade Federal do Rio Grande do Norte (UFRN) matriculados na disciplina de Ensino de Ciências Naturais II.

Em suma, essa produção autoral e original dos alunos do curso de Pedagogia da UFRN teve 
como meta divulgar um resumo semanal do que havia acontecido no mundo científico, cobrindo duas ou mais grandes áreas do conhecimento.

Nesse sentido, o presente artigo consiste no relato dos resultados obtidos com o projeto Essa Semana na Ciência ao longo de três semestres, envolvendo aproximadamente 156 estudantes de Pedagogia. Contempla a organização, as estratégias de método, os resultados do projeto, além dos avanços de um semestre para outro. Teve como objetivos desenvolver, promover e avaliar produções jornalísticas com vistas à popularização da ciência junto aos referidos alunos e à comunidade acadêmica como estratégia pedagógica de aproximação e de diálogo com a cultura científica. 


\section{PERCURSO METODOLÓGICO}

A proposta de popularização da ciência foi desenvolvida nos semestres de 2014.1 a 2015.1 na Universidade Federal do Rio Grande do Norte. Participaram da proposta 156 alunos do curso de Pedagogia matriculados em cinco turmas distintas (diurno e noturno) na disciplina Ensino de Ciências Naturais II, e as atividades contabilizaram uma carga horária de 20 horas/aula no total, para cada turma em cada semestre.

A dinâmica foi proposta no início do semestre, inicialmente como um projeto individual de cada turma. Os alunos deveriam se organizar em cinco grupos distintos, onde cada grupo seria atribuído com um objetivo específico necessário ao funcionamento do projeto geral.

Os grupos que compuseram a proposta foram: 1) os Jornalistas Científicos; 2) os Mediadores; 3) os Editores; 4) a Equipe de Filmagem/gravação; e 5) a Equipe Técnica (Tabela 1).

Tabela 1. Organização do projeto. Estrutura e função detalhada dos grupos componentes da produção jornalística dos alunos de pedagogia da UFRN.

\begin{tabular}{|c|l|c|}
\hline Nome & \multicolumn{1}{|c|}{ Função } & Organização \\
\hline Jornalistas Científicos & $\begin{array}{l}\text { Entrar em contato com as revistas científicas } \\
\text { escolhidas, lendo e resumindo um artigo a cada } \\
\text { semana. }\end{array}$ & Individual ou duplas \\
\hline Mediadores & $\begin{array}{l}\text { Realizar o controle da produção: Recolher os } \\
\text { resumos; Fazer o relatório de rendimento semanal da } \\
\text { turma (entregue ao professor); e entregar a produção } \\
\text { semanal para os editores. }\end{array}$ & Grupo (3 pessoas) \\
\hline Editores & $\begin{array}{l}\text { Revisar, formatar e gerir os textos e imagens para } \\
\text { versão final da edição semanal. }\end{array}$ & Grupo (6 pessoas) \\
\hline Equipe técnica & $\begin{array}{l}\text { Gerenciar os instrumentos de mídia, adicionar efeitos, } \\
\text { imagens, sons, monitorar e postar o conteúdo. }\end{array}$ & Grupo (3 pessoas) \\
\hline Equipe de filmagem/ & $\begin{array}{l}\text { (*No caso de mídia em vídeo) Apresentar e filmar o } \\
\text { material produzido pelos Editores para a edição } \\
\text { semanal. }\end{array}$ & Grupo (4 pessoas) \\
\hline
\end{tabular}

Fonte: Severo (2014).

Foi sugerida aos alunos uma dinâmica semanal que se desdobrou em cinco etapas, cada uma referente a um grupo específico (Figura 1). Na primeira etapa, em duplas (Jornalistas 
Científicos), foram realizadas pesquisas em jornais de divulgação científica e em periódicos especializados para elencar estudos científicos recentes que fossem atinentes à realidade de cada um.

$\mathrm{Na}$ segunda etapa as produções dos Jornalistas Científicos foram entregues ao grupo dos Mediadores, que checavam alguns pontos fundamentais na estrutura do texto de cada dupla: linguagem própria; referência científica nas normas; extensão da matéria; imagem utilizada para referenciar a matéria; e título empregado.

As normas para a produção do texto foram estabelecidas em sala, na presença de todos os grupos. Cito: estar dentro das normas da ABNT; apresentar linguagem clara e de fácil acesso; referenciar o pesquisador realizador do estudo; e estar atento para não cometer plágio.

O controle da produção foi dado a dois grupos específicos (Mediadores e Editores). A escolha por essa estratégia foi muito interessante visto que incentivou a autonomia dos alunos na produção dos textos. Foi perceptível o ganho em densidade e o aumento na complexidade e rigor com o passar das edições. Certamente o fato de não ver o professor como um corretor, ou referencia de verdade, mas como um mediador no processo, deu espaço para que os alunos se auto-regulassem, sendo criteriosos sobre sua própria produção.

$\mathrm{Na}$ terceira etapa, atentos às normas estabelecidas, o grupo de Mediadores entregava a coleção de matérias da semana para os Editores, que tinham como função ler todo o material e certificar-se de que os textos estavam claros para serem lidos por qualquer pessoa e que, mesmo assim, o conteúdo científico havia sido preservado. 
Figura 1. Cronograma de ações por grupo. Estrutura, função e objetivo de cada grupo ao longo da semana para a realização de uma edição semanal do Essa Semana na Ciência.

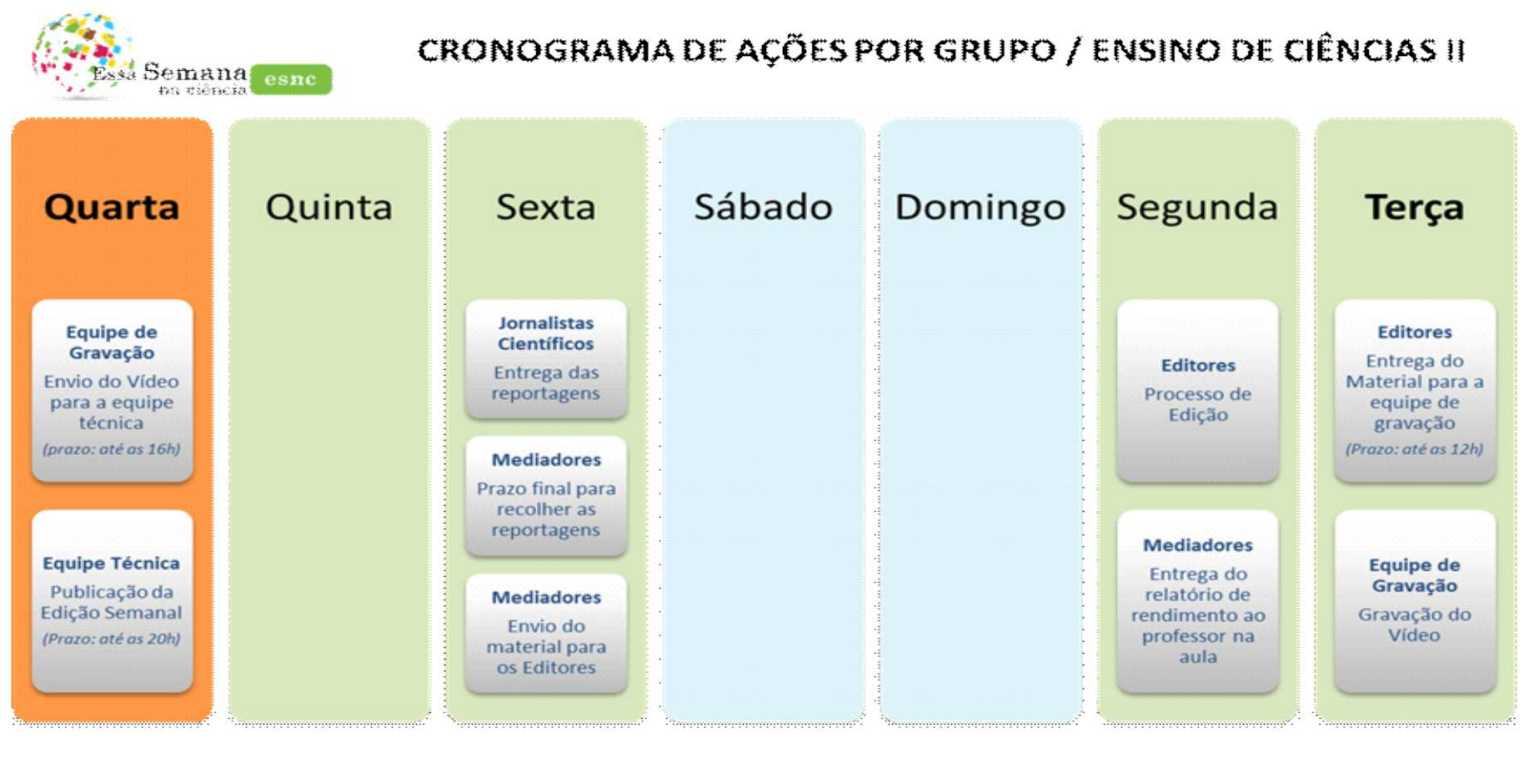

Fonte: Severo (2014)

Aprovados pelos Editores, na quarta etapa, o grupo de gravação recebia a produção semanal para ler e se familiarizarem com os textos. Em seguida eram agendadas sessões de gravação em vídeo do jornal online, tendo dois ou três estudantes como apresentadores um como câmera e um como diretor.

A quinta e última etapa foi a edição e postagem do material audiovisual pelo grupo de Apoio Técnico, que constituiu a identidade visual na forma de jornal publicado em um canal do YouTube (http://goo.gl/utm1Tz). 


\section{RESULTADOS E DISCUSSÃO}

O curso de Licenciatura em Pedagogia possui bases de desdobramento muito amplas. É um engano pensar que os profissionais egressos desses cursos irão lidar apenas com fundamentos e técnicas psico/pedagógico/organizacionais da educação. Os profissionais docentes de pedagogia são habilitados para atuar nas primeiras séries do ensino fundamental e na educação infantil, ou seja, precisam estar habilitados para lidar de forma confortável com conceitos de diversas áreas: ramos das ciências humanas, como história e geografia; ramos da matemática; e ramos das ciências naturais, como química, física, biologia, astronomia e geologia.

Enquanto professores de Ensino de Ciências I e II na Universidade Federal do Rio Grande do Norte percebemos que há certos obstáculos no trabalho com conceitos científicos específicos das ciências naturais, o que é esperado visto que a formação inicial em ciências no nosso país ainda é em grande parte reprodutivista e não pertinente com a realidade e contexto de quem aprende (SCARPA ; SILVA, 2013).

No entanto, é notável nas turmas iniciais uma não familiaridade com o metiê científico e com a forma de construir conhecimento por investigação. Essa situação também foi descrita por Delizoicov, Angoti e Pernambuco (2011), que diagnosticaram uma não afinidade com a narrativa científica por dificuldades na formação inicial, que prioriza os fatos ao invés dos processos que estão contidos e constituem o fenômeno. Ou seja, são validados e postos para utilização na escola apenas uma parcela dos conhecimentos construídos pela ciência, dando ao professor a impressão equivocada de que esta ferramenta é o ponto inicial e final de referência científica.

Tendo em vista que existe esse distanciamento entre os saber e o fazer da ciência; e que há na própria ideia de construção do conhecimento científico obstáculos epistemológicos (BACHELARD, 1995) para grande parte dos alunos de pedagogia, torna-se necessário aproximar os alunos da narrativa científica (VILLANI ; PACCA, 1997). 
O Essa Semana na Ciência teve como meta principal aproximar os alunos de pedagogia e a comunidade da produção científica, raramente utilizada nos cursos de licenciatura, na construção de conhecimento para o ensino de ciências, e muitas vezes de difícil acesso para o consumo da população.

Durante os semestres de 2014.1 a 2015.1 participaram da proposta 156 alunos de graduação em Pedagogia e foram publicadas 91 matérias, que compreenderam as seguintes áreas: tecnologia da informação; ciências biomédicas; C\&T; biotecnologia; astronomia; ensino de ciências. Os estudantes visitaram cerca de 9 portais de divulgação científica nacionais e internacionais e consultaram cerca de 21 periódicos científicos, alguns dos quais referidos por Pinheiro e Valério et. al. (2009) como matrizes de referência para a divulgação científica no Brasil. Sendo eles:

- revista Ciência Hoje, lançada em 1982, e Ciência Hoje das Crianças, em 1986, das mais importantes, e ambas as iniciativas são da Sociedade Brasileira para o Progresso da Ciência (SBPC);

- revista Galileu, da Editora Globo SA (Organizações Globo), em agosto de 1991, inicialmente com o nome de Globo Ciência e "numa linha mais científica do que a atual e da sua concorrente Superinteressante, editada pela Editora Abril";

- Scientific American Brasil, em 2002, publicada pela Editora Duetto, que também lançou História Viva, praticamente ao mesmo tempo que Nossa História, revista publicada pela Fundação Biblioteca Nacional;

- Nexo, revista de difusão científica editada pela Faperj para divulgar os projetos financiados pela Fundação, porém com curta duração;

- a revista Pesquisa Fapesp, lançada em 2001 (PINHEIRO, VALÉRIO et al., 2009, p. 266).

A interação dos alunos com o projeto foi ativa, organizada e mediada pela própria turma, organizados em seis grupos responsáveis por produzir, editar, organizar e gravar as produções semanais. Como eixos de desdobramento, a proposta permitiu dar visibilidade à importantes pesquisas e descobertas científicas recentes e estimular a consulta de pappers 
em periódicos acadêmicos, atividade não comum para os alunos. As atividades de produção e leitura desenvolvida pelos alunos somaram o total de 148 matérias de divulgação científica, das quais listamos apenas alguns na Tabela 2 por motivos de espaço. Os trabalhos atenderam as áreas biomédicas, C\&T, biotecnologia, astronomia e ensino de ciências, totalizando 20 edições em média do jornal em vídeo.

Tabela 2. Algumas matérias de divulgação científica e suas respectivas edições.

\begin{tabular}{|c|c|}
\hline Título da matéria - 2014.1 & Edição \\
\hline O movimento anti-vacina e suas consequências & 1 \\
\hline O sexo do bebê influencia na composição do leite materno & 2 \\
\hline Técnica que usa nanofibra para retirar células cancerígenas é descoberta por especialistas & 2 \\
\hline O dilema da camisinha feminina & 3 \\
\hline Estudo aprimora o diagnóstico do "Teste da orelhinha" & 4 \\
\hline Inflamação no esôfago e a esofagite. Saiba mais sobre esse problema & 4 \\
\hline Amostras de sangue podem gerar células-tronco & 5 \\
\hline Pesquisa aprimora método de detecção de mercúrio em peixes & 6 \\
\hline Tamanho é documento & 6 \\
\hline Antídoto para veneno de cobra & 7 \\
\hline No espaço, com pouca gravidade, os corações ficam esféricos & 7 \\
\hline Homens pensam mais em sexo que as mulheres? & 8 \\
\hline Estudos identificam os fatores da inclusão dos Downs na escola regular & 9 \\
\hline Tratamento da obesidade infantil & 9 \\
\hline Benefícios da música no tratamento e reabilitação de pacientes & 10 \\
\hline Título da matéria - 2015.1 & Edição \\
\hline Freios moleculares - Uma maneira de impedir o crescimento e a disseminação de tumores & 1 \\
\hline Doença e sintomas da febre chicungunha & 1 \\
\hline Hábitos alimentares e riscos de doenças cardiovasculares em universitários & 2 \\
\hline Castanha contra cárie & 2 \\
\hline Uso sustentável da biodiversidade de plantas: benefícios para a saúde humana & 3 \\
\hline Uso do metrô e a sustentabilidade: investindo na qualidade de vida das cidades & 3 \\
\hline Cravo-da-índia no combate à dengue e a malária & 4 \\
\hline Total de matérias & 148 \\
\hline
\end{tabular}

Fonte: os autores (2015). 
Como um desenvolvimento em etapas, os três semestres de 2014.1 a 2015.1, ao compararmos os trabalhos ao longo do tempo percebemos avanços significativos na forma de organizar as produções, valendo-se para tal da utilização como recurso virtual, de um fórum da turma Ensino de Ciências II, criado no Sistema Integrados de Gestão das Atividades Acadêmicas - SIGAA da própria universidade. Vale também ressaltar como sinalização de crescimento, as inovações e a criatividade percebidas para as gravações semanais, sendo utilizados para tal, um aparato maior de equipamentos e recursos tecnológicos. Esses achados, vem de encontro com Masetto (2009) quando esse nos aponta que o uso das tecnologias não se justificam por si mesmas, mas pelos objetivos que se pretenda que elas alcancem, que no caso serão de aprendizagem. 


\section{CONIDERAÇÕES FINAIS}

A fragmentação histórica das ciências naturais da qual decorre a simplificação didática do ensino das ciências naturais é reflexo de um processo historicamente construído. O processo de simplificação do conhecimento exclui da equação os moldes, contextos e implicações pelas quais os conhecimentos foram construídos. É necessário tornar a educação de ciências naturais próxima do conhecimento científico, seus métodos, narrativas e formas de divulgação.

A familiaridade com os textos científicos e o crescente interesse dos alunos por novas fontes de dados ao longo do semestre que desenvolvi essa experiência foram fatores que evidenciaram o envolvimento com atividades associadas a produção, disseminação e uso da narrativa científica.

Desde a observação inicial; a construção de uma ideia para pesquisa; até a aceitação da informação sobre os resultados dessa pesquisa, conhecer os procedimentos da ciência e os conhecimentos científicos atuais são fatores indispensáveis para um ensino de ciências pertinente. Investigar na aproximação dos profissionais docentes, sejam eles da pedagogia ou de qualquer licenciatura, significa, efetivamente, investir em uma atuação profissional sobre a prática social (DELIZOICOV, ANGOTTI et al., 2011), superando a simplificação dos saberes e ampliando um diálogo aberto entre ciência e comunidade.. 


\section{REFERÊNCIAS}

BACHELARD, G. O novo espírito científico. Rio de Janeiro: Tempo Brasileiro, 1995.

BUENO, W. D. C. Jornalismo científico como resgate da cidadania. Em: MASSARANI, L.;MOREIRA, I. D. C., et al (Org.). Ciência e público: caminhos da divulgação científica no Brasil. Rio de Janeiro: Casa da Ciência, UFRJ, 2002., 2002.

. A formação do jornalista científico deve incorporar uma perspectiva crítica. Diálogos \& Ciência - Revista da Faculdade de Tecnologia e Ciências - Rede de Ensino FTC, v. 10, n. 29, 2012.

José Reis: a divulgação científica como compromisso. Comunicação \& Sociedade, v. 24, n. 38, 2002. Disponível em: <https://www.metodista.br/revistas/revistasims/index.php/CSO/article/view/4184 >. Acesso em: 3 fev. 2016.

DELIZOICOV, D.; ANGOTTI, J. A.; PERNAMBUCO, M. M. Ensino de Ciências: fundamentos e métodos. São Paulo: Cortez, 2011.

MORAN, J. M.; MASETTO, M. T.; BEHRENS, M. A. Novas tecnologias e mediação pedagógica. 16a ed. São Paulo: Papirus, 2009.

MORIN, E. Ciência com consciência. 7 ed. São Paulo: Bertrand Brasil, 2003.

PINHEIRO, L. V. R.; VALÉRIO, P. M.; SILVA, M. R. D. Marcos históricos e políticos da divulgação científica no Brasil. Em: BRAGA, G. M. e PINHEIRO, L. V. R. (Org.). Desafios do Impresso ao Digital: Questões Contemporâneas da Informação e Conhecimento. Brasília (DF): IBICT, UNESCO, 2009.

REIS, J.; GONÇALVES, N. L. Veículos de divulgação científica. Em: KREINZ, G. e PAVAN, C. (Org.). Os donos da paisagem: estudos sobre divulgação científica. São Paulo: Publicações NJR, ECA/USP, 2000.

SCARPA, D. L.; SILVA, M. B. E. A Biologia e o ensino de ciências por investigação: dificuldades e possibilidades. Em: CARVALHO, A. M. P. D. (Org.). Ensino de Ciências por Investigação Condições para implementação em sala de aula. São Paulo: Cengage Learning, 2013.

VILLANI, A.; PACCA, J. L. D. A. Construtivismo, conhecimento científico e habilidade didática no ensino de ciências. Revista da Faculdade de Educação, v. 23, 1997. ISSN 0102-2555. Disponivel em: <http://www.scielo.br/scielo.php?script=sci_arttext\&pid=S010225551997000100011\&nrm=iso>. 